\title{
房屋土建工程中的高支模施工技术分析
}

刘子旺

桂林基础设施建设有限公司

DOI:10.32629/btr.v2i9.2496

[摘 要] 随着经济的不断发展, 房屋土建工程的数量也随之增加, 其中应用的技术也在进行着更新。其中, 高支模施工技术随着 对房屋质量的要求越来越高,这项技术也在应用过程中得到了完善。但从实际情况来看,高支模技术在用于房屋土建工程的过 程中仍然存在着较多的问题。本文简述了土建工程中应用高支模施工技术的重要意义, 就应用过程中的技术要点进行了分析, 并提出了提高高支模施工质量的具体措施。

[关键词] 房屋土建工程; 高支模技术; 要点与措施

经济的发展带动了城市发展速度, 城市的人口数量随之 大量增加。为了应对这一情况, 城市启动了大量的房屋土建工 程项目, 并以此作为城市发展过程中的工作重点。另外, 经济 的发展同样使人们对于房屋建筑的质量有了新的要求, 不仅 要注重其功能性, 还要在保证其质量的基础上提升其美观度, 这就给当下的房屋土建工程的承包方带来了新的挑战 ${ }^{[1]}$ 。高 支模施工技术作为目前使用的主要施工技术类型, 决定着建 筑的最终实效性与功能性, 同时也决定着房屋的质量, 因此 需要施工管理人员格外注意。但由于高支模施工技术在我国 的应用时间并不长, 因此在实际的施工过程中应用高支模技 术依然存在着较多问题。

\section{1 土建工程中应用高支模施工技术的重要意义}

对于建筑来说, 最重要的就是其质量与功能性, 这也是 人们在不断提高的生活条件下尤其看中的两点。当下人们对 建筑的要求不仅仅是只要满足功能性即可, 在保证其质量与 舒适度的同时, 也需要在保证其质量的基础上提升外形结构 设计美观度。而高支模技术作为保证建筑功能性以及整体结 构稳定性的主要技术, 为提高建筑的整体承载力打下了良好 的基础。另外, 其还具有美化土建工程外形结构的优势, 在保 证质量的同时也满足了人们对于建筑越来越高的综合要求 ${ }^{[2]}$ 。 再加上高支模施工技术的应用特点, 能够大大减少了过程中 使用的施工材料, 从而降低了实际的工程修建成本, 这一优 势也使得其被越来越多的施工单位所应用。但高支模施工技 术并不是完美的, 其对于施工人员的专业水平以及个人身体 素质都有着极高的要求。其从技术应用特点来说是一种高危 技术, 因此在确定在土建工程中使用此项技术前应核查建筑 物的整体高度, 分析有关建筑的各种数据, 例如建筑物之间 的跨度以及应用模板材料的质量与其荷载能力, 并将其与正 常要求的模板材料荷载能力进行比对, 判断其是否能够继续 应用以及应用后是否能够起到设计方案中预计的模板支撑 作用 ${ }^{[3]}$ 。尤其要注意的是, 在实际的施工过程中, 不仅应遵循 基本的操作流程, 还应保证每个施工人员都能够按照图纸要 求进行施工, 并派质量监督人员规范工人的施工动作, 以满 足高支模施工技术的应用标准。高支模施工技术是否在应用
过程中得到了规范化的执行, 是提高土建工程整体质量与其 功能性的关键。

\section{2 高支模施工技术的要点分析}

2.1 高支模的检查

由于高支模施工技术的应用特点, 使得其对操作人员的 专业要求非常高, 无论是起初的支架安装还是高支模应用效 果核查, 都需要专业的技术人员组织实施, 以保证高支模技 术的应用效果。另外, 尤其是支架安装, 更是需要注意到技术 交底工作的重要性, 高支模安装时技术的应用初段, 是技术 效果的重要基础, 因此要在工作前设计好衔接程序并要时刻 注意操作人员在这一过程中的人身安全。高支模施工顺序以 及操作规范都需要技术人员与操作人员详细了解, 同时按照 相关规定落实好每个施工人员的责任和工作任务 ${ }^{[4]}$ 。在高支 模安装完毕后, 应派专业的质量核查人员进行检查, 使安装 施工过程达到技术应用目标。在施工期间, 应以工程质量监 督体系为领导核心, 不仅要规范操作人员的工作步骤, 也要 提高施工人员的技术水平, 并要保证在每一步骤的高支模施 工环节进行时都有技术人员在旁进行技术指导, 若是过程中 发现有任何问题都应及时记录, 将问题汇总后汇报给上级。 另外, 技术人员也应对问题进行详细分析, 找出其中的关键 点以及时解决问题。

2.2 模板安装

模板安装是高支模施工技术应用过程中的主要环节, 应 引起技术人员与施工人员的注意。目前, 模板安装主要使用 的是木质模板, 这种模板具有一定的应用优势, 是保证施工 人员在模板拼接与安装过程安全的重要基础, 因此应尤其注 意模板质量 ${ }^{[5]}$ 。在使用木质模板进行安装以及拼接时, 应考 虑到可能发生的不确定因素影响到模板安装的质量, 预留出 一定缝隙保证模板不会受到潮湿天气影响, 避免发生变形等 现象。

\section{3棱面支撑安装}

棱面支撑安装的关键在于必须标齐梁与轴线, 另外还需 要在保证其水平高度的基础上提升脚手架的安装稳定性。其 中, 脚手架的拼接的两部分: 安装与固定, 均需要保证脚手架 
的平齐以及稳定性。施工人员在固定脚手架时, 应仔细查看 是否在水平线上, 利用联结装置将脚手架的各个节点锁紧。 通过对部分案例的分析, 发现棱面支撑安装环节出现事故的 原因就在于脚手架的稳定性, 部分工人为了方便只对主要部 位进行锁紧, 这样极大的降低了脚手架的稳定性 ${ }^{[6]}$ 。一旦有 一个联结点脱落, 势必会增大其他联结点的承受压力, 再加 上联结点的数量过少, 就会增大施工人员出现危险的概率。

2.4外框架柱梁安装

外框架柱梁的安装并不是一次进行, 而是需要将这一过 程分为多个环节以保证安装稳定性。首先应对柱子与梁板进 行浇筑, 在确定浇筑完成后就要利用排架为外框架柱梁安装 到井字梁屋盖的过程提供支撑尤其是各层柱梁之间的支撑, 应对脚手架的拉结进行加固以保证稳定性。接着为了进一步 增强柱梁水平支撑与脚手架间的连接稳固性, 需要采取一定 措施使二者紧密衔接。在完成脚手架固定后, 应全面检查其 稳定性, 并进行后续的混凝土浇筑施工, 采取的浇筑顺序是 先中间再两端, 并要及时平铺浇筑材料。

\section{5 高支模验收}

高支模的验收环节同样质量核查人员有着严格的要求, 不仅应在验收前对这些人员进行培训, 还应提高质量和产人 员的专业素质, 应确保其有足够的工作能力后才允许其进行 高支模的验收工作 ${ }^{[7]}$ 。土建施工进行前, 首先要查看设计要 求是否符合高支模技术的应用标准, 另外还需要进行细致的 检查以提升技术的应用质量。而对于施工单位整体来说, 建 立一个质量监管部门是非常有必要的, 既能够保证操作规范, 还能够在高支模验收过程中及时发现其中存在的问题, 避免 遗留下安全隐患对土建工程产生影响。

\section{6 拆除高支模}

高支模的拆除是整个高支模技术应用的最后一步。在施 工人员完成所有的建筑施工过程后, 应及时拆除高支模。拆 除前, 施工人员应对混凝土的强度做最后检查, 确定其符合 相关标准后才能拆除高支模。施工人员应保证模板的拆除顺 序, 并对整个高支模技术应用环节中使用的支架以及配件进 行清理, 以方便下次施工时使用。

\section{3 提高高支模施工质量的具体措施}

3. 1 提高高支模施工质量 想要提高高支模施工质量, 就应该规范每一个施工环节,
尤其是高支模施工方案方面的设计, 更应该在详细考察后规 划好后续的施工步骤。在确定施工方案后, 应组织专业人员 对设计图进行二次核查，确保其在符合工程实际特点的同时， 也具备可操作性; 而施工原材料质量的保证同样也很重要。 在采购原材料时, 必须向厂家索要合格证以及对应的性能试 验证明, 以保证最后的工程质量; 混凝土振捣是浇筑过程中 的重要环节, 想要保证工程质量就必须要保证过程具有紧密 型与均匀性, 避免出现漏浆等现象; 高支模施工全部完毕后, 应以高支模的验收标准为依据保证高支模的质量。

\section{2 保障高支模施工安全}

施工人员的技术水平决定了高支模技术的应用效果, 以 此应保证每个工作人员都了解相关知识, 避免在操作过程中 由于操作不当伤害到自己或他人; 使用现场的安全宣传同样 重要, 每个施工人员都应了解到足够的安全知识, 从而升操 作过程中的安全性; 施工现场的安全巡查仍存在着力度不够 的问题, 应增大巡查力度, 并对发下的安全隐患及时整改, 为 高支模施工质量的提升打下基础。

\section{4 结束语}

综上所述, 高支模技术在土建工程中的大量应用是未来 的发展趋势, 想要提高其技术应用质量就必要要对其技术应 用流程进行分析, 并在不断的实践中完善高支模应用技术, 为未来土建工程的进一步发展打下坚实的基础。

\section{[参考文献]}

[1]章兴.高支模施工技术在建筑工程施工中的应用研 究[J].建材与装饰,2016,(10):38-39.

[2]解炜。探究高支模施工技术在厂房施工中的应用 [J]. 价值工程,2018,37(20):231-232.

[3] 张中堂.高支模施工技术在土建工程中的应用探讨 [J].装饰装修天地,2019,(5):296.

[4]徐锡凯.房建土建工程中高支模的施工技术[J].山东 工业技术,2016,(1):110-111.

[5]白亚朋.房建土建工程中高支模施工技术的思考 [J]. 建筑工程技术与设计,2017,(31):207.

[6]李军龙.高支模施工技术在土建施工中的应用解析 [J].建材发展导向(上),2017,15(10):31-32.

[7]吴南寿.对房建土建工程中的高支模施工技术的探讨 [J].建筑工程技术与设计,2017,(32):284. 